\title{
Digital Transformation of Oil and Gas Sector during Transition to Renewable Energy Sources
}

\author{
Valeriy M. Tumin ${ }^{1 *[O R C I D}$ 0000-0003-4651-0359], \\ Alexey S. Kharlanov 2[ORCID 0000-0002-6427-8808], \\ Elena V. Zenkina 3[ORCID 0000-0003-2192-4715], \\ Petr A. Kostromin 3[ORCID 0000-0003-4161-3244], \\ Vladimir A. Trifonov 4[ORCID 0000-0003-2815-3749]
}

\author{
${ }^{1}$ Moscow Polytechnic University, Moscow, Russia \\ ${ }^{2}$ Diplomatic Academy of the Ministry of Foreign Affairs of the Russian Federation, Moscow, Russia \\ ${ }^{3}$ Russian State University for the Humanities, Moscow, Russia \\ ${ }^{4}$ Yaroslav-the-Wise Novgorod State University, Veliky Novgorod, Russia \\ vm@tumin.net
}

\begin{abstract}
Modern energy sector is going through the era of quantitative and qualitative changes which influence all its stakeholders: companies manufacturing and consuming energy, state, population, environmental protecting organizations. This process cannot be accurately predicted since oil, gas and coal mining companies resist changes in some degree, because the fourth energetic transition means the replacement of traditional carbohydrates and fossil fuel with innovative sources: sun, wind, geothermal energy. Their proportion in the world energy consumption is still small but grows increasingly. Therefore, the final energy balance of countries and territories is still unknown just as exact directions of export and import of such energy resources are unknown, since countries that previously only imported oil and gas can become new world leaders in the pure energy production. The fact that this problem is urgent in Russia does not cause any doubt due to the "Dutch disease" of economics, i.e. the dependence of the country budget on world prices for fossil fuel. At the same time, our country has a high potential of renewable sources, at least, wind energetic. The article reviews literature on approaches to industrial digital transformation and the place of renewable energetic in future business models. The transition to digital transformation is aligned with the UN Sustainable Development goals and the goals of the Paris Climate Agreement. The theory of energy transitions by V. Smil is assessed by the authors as one of the most promising theories which describe the future of world energy and the place of renewable sources in it. The authors consider the dynamics of primary energy consumption in the world and curves of learning which show the growth of economic efficiency of renewable and non-traditional sources in comparison with traditional fossil fuels. The authors draw the conclusions about promising trends of the world energy development in the context of digital transformation.
\end{abstract}

Keywords: digital transformation, energy transition, non-renewable energy resources, oil and gas sector, renewable energy sources

\section{INTRODUCTION}

Currently, there is a demand for energy resources, which is caused by the development of world GDP. According to experts, digital transformation as an industrial branch can be the best technology to optimize all available energy sources both underground and renewable. The energy consumption crisis that humanity faced in the 1970s demonstrated all drawbacks and waste in the global energy use. It was then that the transition to modern renewable energetic and the remaking of the global energy market was laid. In addition, climatic problems began to arise [1]. Recent trends include 
price (sharp fluctuations in energy prices) and psychological (the accident at the Fokushima NPP) shocks.

The sighing of the Paris Agreement in 2015 became an important milestone in countries moving towards a carbon-free economy and less reliance on fossil fuels [2]. The UN also highly estimates climatic risks and has repeatedly stated in its reports that human activities are the main cause of the rise in global average temperatures. In the future, it will result in a decrease in yields, an increase in income gap along the North-South line, and a total migration crisis [3].

In their study, A. Lohrmann et al. indicate that renewable energy sources will facilitate access to clean water in the short term, and reduce the average cost of water and foods in the long term [4].

Currently, about $25 \%$ of the global electricity production is provided by renewable energy, of which about $10 \%$ is due to innovative technologies. The article by M. Ram et al. demonstrated that wind turbines and solar panels can be more cost competitive than fossil fuels and even NPPs [5].

There are a variety of scenarios for reducing greenhouse gas emissions. Thus, for example, the International Energy Agency admits the presence of $\mathrm{CO}_{2}$ emissions after 30 years, as well as the possibility to use nuclear energy. However, this is not complied with the Paris Climate Agreement. During the period of 10 years to 2017 , emissions of carbon dioxide increased by $1.5 \%$, therefore, the goals of the Paris Agreement are not fully met [6].

Studies by A. Grubler et al. showed that the use of renewable energy could lead to a decrease in the global energy demand due to an increase in efficiency of using available supplies [7]. The TIME-VTT, GENeSYS-MOD models make it possible to mathematically evaluate the available stocks, consumption rates and waste quantities on a global scale $[8,9]$.

In their research, K. Hansen et al. revealed the prospects for production of synthetic fuels instead of more common biofuels. This is done to ensure that biofuels do not take land for agricultural needs [10].

The pandemic of COVID-19 made it urgent to take management decisions on the transition to digital economy and digital transformations. However, the very approach to the essence of this concept (digital transformation) remains not fully resolved. The work of K. Schwab defines digital transformation as the interweaving of information system with biophysical one [11].

The research of G. Vial is one of the most comprehensive in terms of approaches to digital transformation [12].

Taking into account the purpose of this article, we define digital transformation as a set of innovative technologies for creating business network and forming the architecture of business systems of the digital economy. Such processes of creating network are observed both in production and in delivery and sale of energy sources [13].

Though it is possible to find almost any information about modern energy technologies by the way of a patent search, these technologies cannot be introduced into practice without the know-how. As a result, you will lag behind your competitors already at initial stages of an innovative cycle if you do not know production secrets $[14,15]$.

In his work, A. Kusiak shows the relationship between digital transformation and sustainable development of enterprises and territories [16]. He introduces the concept of "design for sustainability", which, in our opinion, best reflects the goals of digital transformation. Based on the results of the literature review, we may conclude that digital transformation acts on the energy sector as follows:

1) reduces fixed production costs;

2) contributes to energy saving;

3) increases productivity;

4) increases innovation potential.

In this regard, it is very interesting to consider modern trends in the field of renewable energy in the oil and gas industry [17].

\section{MATERIALS AND METHODS}

The purpose of this work is to assess the change in the structure of the world energy sector using the example of the oil and gas industry. Based on the study purpose, we distinguish the following tasks:

- description of the modern process of digital transformation;

- determination of the most effective options to adapt to new digital realities;

- identification of the most promising technologies of renewable energy; 
- assessment of prospects for development of the energy sector.

In the article, we use data from the Skolkovo Energy Center of the Moscow School of Management, the Energy Research Institute of the RAS. The theoretical basis of the article is the theory of energy transitions by V. Smil.

From our point of view, key limitations of conclusions and results of the work are in the fact that innovations are not equally adopted in different countries, which may hinder the implementation of the Paris Climate Agreement by 2050.

\section{RESULTS}

According to V. Smil, the world is currently in the process of the forth energy transition. The essence of this transition is the change of the energy consumption structure and introduction of improving innovations [18, 19]. Similar processes were observed back in the $19^{\text {th }}$ century, when coal displaced biomass in the consumption structure. Then oil displaced coal (the second energy transition was around 1970). In our time, gas has displaced oil (the third energy transition, 2010). The fourth energy transition will be the transition to non-traditional energy sources: wind, solar, geothermal, tidal ones.

Historically, energy transfers are impossible without large investments and high costs, but the economies of scale give hope that the cost of one kilowatt of energy obtained from non-traditional sources will decrease [20]. In any case, the oil and gas industry will face an inevitable decline due to reduced reserves. At the same time, modern investors do not want to invest in high-risk technologies not fully tested [21]. In order to develop a successful strategy for the transition to renewable energy sources, one needs to understand general principles of energy transition and have the notion of energy balance. The rate of energy transition is a priority factor for successful investments in this industry. However, current data to accurately evaluate the rate of completion of the fourth energy transition do not yet exist.

One of the models was prepared by the Energy Research Institute of the RAS and the Skolkovo Energy Center of Moscow School of Management (Figure 1).

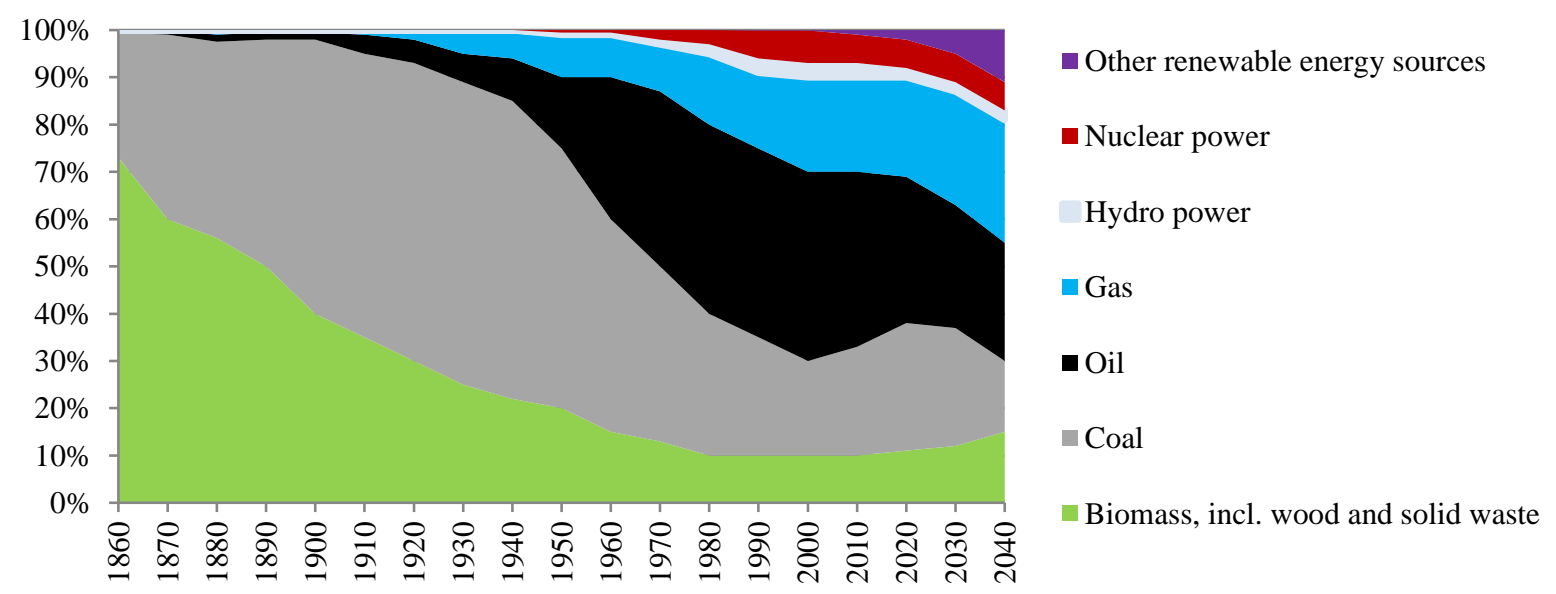

Figure 1. Dynamics of the structure of primary energy consumption in the world from 1860 to the present time, and forecast until 2040

Source: Compiled by the authors based on the data [22, 23]

According to the above data, from 2000 to 2018 , the total capacity of all renewable and nontraditional energy sources increased by 21 times, and the share in the energy consumption structure increased by 3 times [22].

The evident example of an increase in economic efficiency of renewable energy is a so-called "learning curve". It illustrates economies of scale, i.e. the reduction in the cost of innovative technologies thanks to their mass use. Let us consider the most popular sources of renewable energy and the change in the cost of one kilowatthour in 2020 compared to 2010 (Figure 2).

According to the above data, it can be concluded that solar panels demonstrate the greatest efficiency and the greatest reduction in the unit cost of use. The average cost of producing one kilowatt-hour using similar technologies is about 8.5 cents, which is comparable to traditional fuel energy. Also, experts note the potential of offshore wind turbines. 


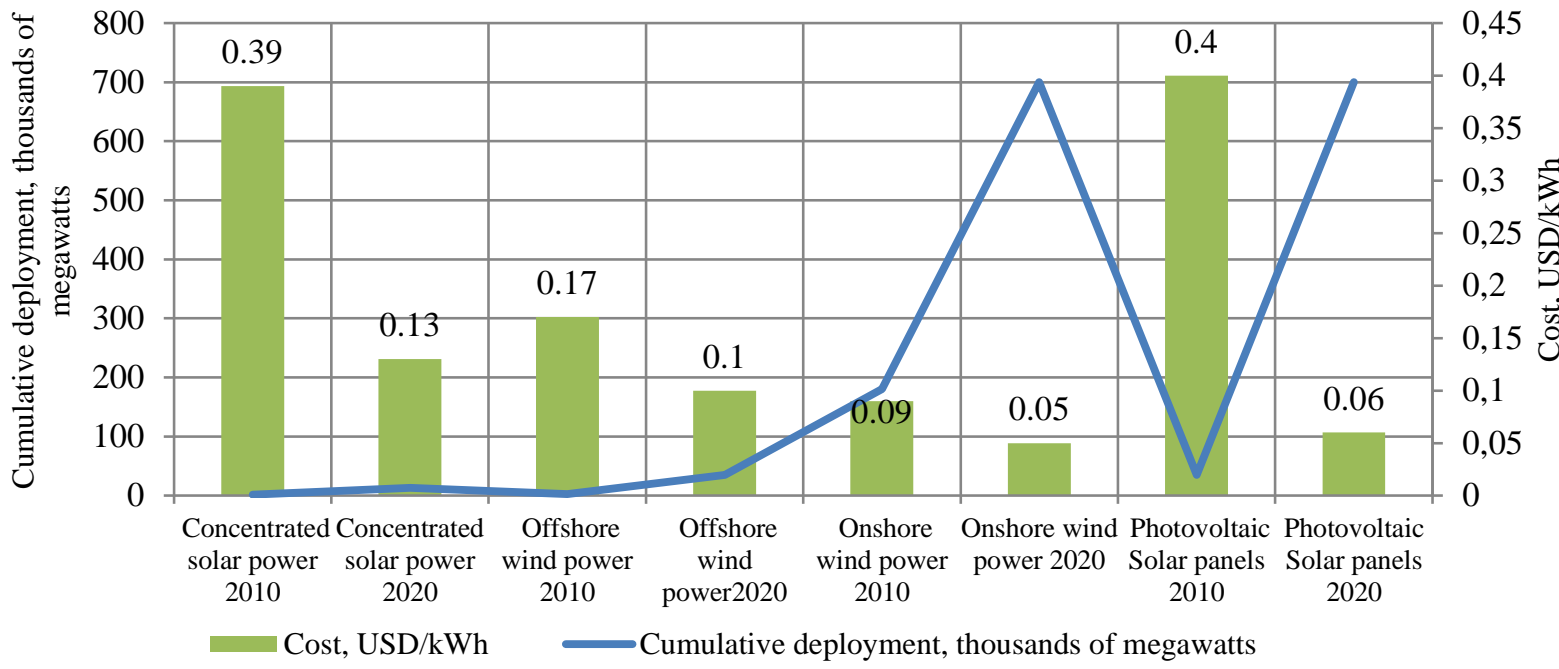

Figure 2. Learning curve for basic renewable energy technologies, 2010-2020

Source: Compiled by the authors based on the data $[22,23]$

Today, such a transition is performed not only by European countries (Sweden, France, Holland), but also by China. Their strategy is to generate about $1 / 3$ of electricity from renewable sources. In the USA, the Giga-Watt Club project is being implemented: solar panels are installed on roofs of houses in "sunny" states (Florida, California, Nevada, Texas). Tesla is also actively involved in the solar energy movement: it completely built up the island Kauai in Hawaii with solar panels.

In 2012, in Russia, the law 'On Promotion of Use of Renewable Energy Sources in Retail Electricity Markets' was adopted. However, it should be noted that heat energy still occupies more than $2 / 3$ of Russian electricity production (Table 1).

Table 1. Structure of electricity production in Russia, 2018

\begin{tabular}{|l|c|}
\hline \multicolumn{1}{|c|}{ Energy source } & Share, \% \\
\hline Heat energy & 68.74 \\
\hline Nuclear energy & 10.97 \\
\hline Hydro energy & 19.9 \\
\hline Renewable energy & 0.39 \\
\hline
\end{tabular}

Source: Compiled by the authors based on the data [24]

In this process, subsidies and grants are very important, especially for the production of spare parts, for example, blades for wind turbines made of composite materials that can withstand wind loads; coatings for solar panels with the best light absorption coefficient [25, 26].

\section{DISCUSSION}

The global energy system will face fundamental changes. In general, domestic and foreign studies are consistent with the goals and development indicators of the UN. We believe that the introduction of renewable energy technologies will be possible only when the cost of these technologies becomes lower than that of traditional oil, gas and coal mining. This is the only way to implement the Paris Climate Agreement and prevent an average global temperature rise of $1.5^{\circ} \mathrm{C}$.

All modern technologies are based on electricity, so it is necessary to strike a reasonable balance between total electrification and sustainable electricity consumption. The driver of this process is the IT industry.

\section{CONCLUSION}

The study allowed us to draw the following conclusions.

1) Digital transformation of the oil and gas industry is possible only on principles of defossilization of industries related to oil and gas: from the production of clothing to the production of drugs and polymer composite materials.

2) Growth in demand for power generation capacities will help reduce the cost of solar and wind energy.

3) 3) In general, a successful transition to renewable energy sources will be possible only if a positive energy balance and positive economic efficiency of its use are ensured, that is, there is a certain minimum profitability threshold below which investors 
will not invest in unprofitable projects. Therefore, the task of international business is to increase the availability of such technologies for countries with middle and low income. For example, African countries have huge potential but unused reserves of solar energy. At the same time, the demand for it, especially in million-plus cities (Kinshasa, Lagos, Cairo), would be very high.

\section{AUTHORS' CONTRIBUTIONS}

The study was carried out by five authors. Valeriy M. Tumin and Vladimir A. Trifonov analyzed the "learning curve", existing innovative renewable energy technologies. Alexey S. Kharlanov analyzed the global dynamics of energy transitions and reviewed forecasts up to 2050. Elena V. Zenkina substantiated the importance of the energy transition for the world economy, presented examples of foreign companies and projects. Petr A. Kostromin completed the literature review and formulated conclusions.

\section{REFERENCES}

[1] O.Y. Myasnikova, I.I. Shatalova, E.V. Zenkina, T.V. Bogacheva, et al., "Promising directions of cooperation among Eurasian Economic Union countries", International Journal of Engineering and Technology, 2018, vol. 7(3.14), pp. 386391. DOI: 10.14419/ijet.v7i3.6.16009

[2] D. Bogdanov, M. Ram, A. Aghahosseini, A. Gulagi, et al., "Low-cost renewable electricity as the key driver of the global energy transition towards sustainability", Energy, 2021, vol. 227, p. $120467 . \quad$ DOI: 10.1016/j.energy.2021.120467

[3] "Global sustainable development report 2019: the future is now e Science for Achieving Sustainable Development". United Nations, New York, 2019. Retrieved from https://sustainabledevelopment.un.org/content/d ocuments/24797GSDR_report_2019.pdf

[4] A. Lohrmann, J. Farfan, U. Caldera, C. Lohrmann, et al., "Global scenarios for significant water use reduction in thermal power plants based on cooling water demand estimation using satellite imagery", Nature Energy, 2019, vol. 4, pp. 1040-1048. DOI: 10.1038/s41560-019-0501-4

[5] M. Ram, M. Child, A. Aghahosseini, D.
Bogdanov, et al., "A comparative analysis of electricity generation costs from renewable, fossil fuel and nuclear sources in G20 countries for the period 2015-2030", Journal of Cleaner Production, 2018, vol. 199, pp. 687-704. DOI: 10.1016/j.jclepro.2018.07.159

[6] C.L. Quéré, R.M. Andrew, P. Friedlingstein, S. Sitch, et al., "Global Carbon Budget", Earth System Science Data, 2018, vol. 10, pp. 21412194. DOI: $10.5194 /$ essd-10-2141-2018

[7] A. Grubler, C. Wilson, N. Bento, B. Boza-Kiss, et al., "A low energy demand scenario for meeting the $1.5^{\circ} \mathrm{C}$ target and sustainable development goals without negative emission technologies", Nature Energy, 2018, vol. 3, pp. 515-527. DOI: 10.1038/s41560-018-0172-6

[8] E. Pursiheimo, H. Holttinen, T. Koljonen, "Inter-sectoral effects of high renewable energy share in global energy system", Renewable Energy, 2019, vol. 136, pp. 1119-1129. DOI: 10.1016/j.renene.2018.09.082

[9] K. Löffler, K. Hainsch, T. Burandt, P-Y. Oei, et al., "Designing a Model for the Global Energy System - GENeSYS-MOD: An Application of the Open-Source Energy Modeling System", Energies, 2017, vol. 10(10), p. 1468. DOI: 10.3390/en10101468

[10]K. Hansen, C. Breyer, H. Lund, "Status and perspectives on $100 \%$ renewable energy systems", Energy, 2019, vol. 175, pp. 471-480. DOI: $10.1016 /$ j.energy.2019.03.092

[11]K. Schwab, "The fourth industrial revolution", Currency, 2017. Retrieved from https://law.unimelb.edu.au/_data/assets/pdf_file /0005/3385454/Schwab-

The_Fourth_Industrial_Revolution_Klaus_S.pdf

[12] G. Vial, "Understanding digital transformation: a review and a research agenda", Journal of Strategic Information Systems, 2019, vol. 28(2), pp. 118-144. DOI: 10.1016/j.jsis.2019.01.003

[13] M.D. Jones, S. Hutcheson, J.D. Camba, "Past, present, and future barriers to digital transformation in manufacturing: A review", Journal of Manufacturing Systems, 2021. DOI: 10.1016/j.jmsy.2021.03.006

[14]L.S. Valinurova, E.A. Sulimova, T.G. Guseva, E.A. Bolotina, V.M. Tumin, "Post-crisis modeling of economic development trends in an on-going recession of national economies", Montenegrin Journal of Economics, 2021, 
vol. 17(2), pp. 75-82. DOI: 10.14254/1800$5845 / 2021.17-2.6$

[15] V. Govindarajan, J.R. Immelt, "The only way manufacturers can survive", MIT Sloan Management Review, 2019, vol. 60(3), pp. 2433.

[16]A. Kusiak, "Open manufacturing: a design-forresilience approach", International Journal of Production Research, 2020, vol. 58(15), pp. 4647-4658.

DOI: $10.1080 / 00207543.2020 .1770894$

[17] S. Lange, J. Pohl, T. Santarius, "Digitalization and energy consumption. Does ICT reduce energy demand?", Ecological Economics, 2020, vol. 176, p. $106760 . \quad$ DOI: 10.1016/j.ecolecon.2020.106760

[18] V. Smil, "Energy (r)evolutions take time", World Energy, 2019, vol. 44, pp.10-14.

[19] V. Smil, "Examining energy transitions: A dozen insights based on performance", Energy Research \& Social Science, 2016, vol. 22, pp. 194-197. DOI: 10.1016/j.erss.2016.08.017

[20]B. Fattouh, R. Poudineh, R. West, "The rise of renewables and energy transition: what adaptation strategy exists for oil companies and oil-exporting countries?", Energy Transit, 2019, vol. 3, pp. 45-58. DOI: 10.1007/s41825-01900013-x

[21]B.S. Vasyakin, D.N. Mednikov, E.A. Karelina, A.S. Kharlanov, "Marketing model of distribution of intellectual machines as new subjects of socio-economic relations in emerging economies", International Journal of Economic Policy in Emerging Economies, 2021, p. 10038315 . DOI: 10.1504/LIEPEE.2021.10038315

[22] “Global and Russian Energy Outlook 2019”. (In Russ.). Retrieved from https://www.eriras.ru/files/forecast_2019_en.pdf

[23] A.S. Kharlanov, "Gas Oil sector by industry 4.0: Transfer to renewable energy sources and digitalization results", Modern Management Technology, 2021, vol. 2(95), p. 9508. (In Russ.).

[24] "Distributed energy resources in Russia: Development Potential”, 2018. (In Russ.). Retrieved from https://energy.skolkovo.ru/downloads/document s/SEneC/Research/SKOLKOVO_EneC_DER_2 018.10.09_Eng.pdf

[25]C. Brognaux, E. Boudier, E. Hegnsholt, A. Porsborg-Smith, "The Multiple Paths to Peak Oil Demand", BCG, 2017. Retrieved from https://www.bcg.com/publications/2017/energyenvironment-upstream-oil-gas-multiple-pathspeak-oil-demand

[26]H. Ellyatt, "Global oil demand to peak around 2040 or 'much sooner,' IMF says", CNBC, 2020. Retrieved from https://www.cnbc.com/2020/02/06/global-oildemand-to-peak-around-2040-imf-says.html 